\title{
CRISIS, CENSURA Y BÚSQUEDAS DE LA INDUSTRIA DEL CINE MEXICANO EN LOS AÑOS CINCUENTA. EL CASO DE SOMBRA VERDE DE PRODUCCIONES CALDERÓN
}

\author{
Fernando Mino Gracia ${ }^{1}$ \\ Centro de Investigaciones y Estudios Superiores \\ en Antropología Social-Pacífico Sur
}

$\mathrm{F}^{1}$ presente trabajo se concentra en describir el proceso de producción de la película Sombra verde (Roberto Gavaldón, 1954), un caso representativo que nos permite explorar las complejas condiciones gremiales en que era producido el cine nacional, así como las dificultades que enfrentaba en términos de comercialización en una época de transformaciones profundas en el negocio, con el incremento de la competencia de Hollywood en el mercado mexicano y latinoamericano, además de la amenaza, todavía incipiente, de la televisión. Asimismo, da cuenta de las tensiones, imposiciones y acuerdos entre la industria cinematográfica mexicana y la idea de censura imperante

Fecha de recepción: 6 de febrero de 2018

Fecha de aceptación: 9 de octubre de 2018

${ }_{1}$ Para la realización de este ensayo recibí aportes fundamentales. Agradezco a Paulina Suárez-Hesketh su generoso apoyo para recabar los documentos del Permanencia Voluntaria Archivo Cinematográfico, acervo que resguarda los archivos de la familia Calderón. También agradezco a Xóchitl Fernández, del Archivo Fílmico Agrasánchez, por su acuciosa selección de notas periodísticas. 
durante los años cincuenta del siglo pasado, justificada por la necesidad de impulsar un cine de "elevada calidad moral y artística" e "interés nacional”, una preocupación latente desde la industrialización del cine mexicano y, desde 1947, una responsabilidad legal del Estado. ${ }^{2}$

Durante la década de 1950 el cine mexicano, que los tres lustros previos había construido una industria sólida e influyente en toda la América de habla española, experimentó un desplome gradual y sostenido: se limitó su acceso a las pantallas nacionales, su mercado continental se contrajo paulatinamente y su financiamiento se vio afectado por la presión permanente de una política pública concentrada en mejorar la "calidad", definida por criterios oficialistas, de las películas nacionales. ${ }^{3}$

Este proceso no fue fácilmente identificable por los involucrados en la industria cinematográfica del periodo señalado, pues en general se veían beneficiados, todavía, por altos ingresos económicos, estaban protegidos por poderosos sectores gremiales y se consideraban aliados sólidos del régimen y de su política propagandística. En consecuencia, sus estrategias para sortear la crisis fueron aisladas, infructuosas y a menudo contraproducentes. La realización de Sombra verde por Producciones Calderón se inscribe en esta atmósfera cultural y económica, y se

\footnotetext{
${ }^{2}$ La Ley que crea la Comisión Nacional de Cinematografía (1947) dio a esta nueva entidad la responsabilidad de "fomentar la producción de películas de alta calidad e interés nacional” (Art. 2, fracción I), Diario oficial (31 dic. 1947), p. 4. La Ley de la Industria Cinematográfica de 1949, que derogó a la anterior, estableció la obligación del Estado de resolver los "problemas relativos a la cinematografía, velando por su elevación moral y artística" (Art. $1^{\circ}$ ), y de "fomentar la producción de películas de alta calidad e interés nacional” (Art. $2^{\circ}$, fracción I), Diario oficial (31 dic. 1949), Sección segunda, p. 3.

${ }^{3}$ La historiografía del cine mexicano coincide en señalar el inicio de la crisis del cine mexicano en la década de los cincuenta, y describe los factores señalados como las causas principales. CosTA, La 'apertura' cinematográfica; GARcía Riera, Breve historia del cine mexicano, primer siglo 1897-1997; Peredo, Cine y propaganda para Latinoamérica.
} 
distinguió por su intento de cumplir con los estándares del "cine de calidad” y, al mismo tiempo, por su pretensión de ampliar su mercado hacia el consumidor anglosajón de Estados Unidos.

La política de impulso al "cine de interés nacional" y al "cine de elevada calidad" - un par de conceptos difusos, maleables y a menudo intercambiables, según las necesidades de representación del régimen en turno- ${ }^{4}$ se afianzó con la llegada, en 1953, de Eduardo Garduño a la dirección del Banco Nacional Cinematográfico, ${ }^{5}$ refundado para ampliar su capital e integrar

${ }^{4}$ La noción de un cine de "interés nacional" está ligada a su supuesta capacidad de fortalecer la idea de nación mediante la construcción de relatos donde funcionaran cabalmente las estructuras y funciones reconocidas legítimamente del Estado; dicha noción está ligada al cine mismo desde sus primeros años, pero se intensificó a partir de que la producción nacional comenzó a despuntar durante los años treinta. Rosario Vidal Bonifaz desarrolla el tema para el periodo cardenista en "Racionalidad burocrática y dominación carismática". Por su parte, Juan Manuel Aurrecoechea, en "Figueroa, educador visual", explora el asunto durante los primeros años cuarenta cuando, en el contexto de la guerra mundial, tomó fuerza la idea del cine como un medio de "educación visual”. En los años cuarenta también comenzó a despuntar la idea de un "cine de calidad", es decir, aquel capaz de conciliar el interés nacional con el artístico e, incluso, el comercial, por medio de una propuesta narrativa y estética reconocida por instituciones, nacionales o extranjeras, validadas para tal propósito, ya fueran festivales o academias, como la recién creada Academia Mexicana de Cinematografía, dedicada a premiar a las películas nacionales con mayores méritos; por cierto, la estética de los filmes fotografiados por Gabriel Figueroa (en particular los dirigidos por Emilio Fernández) fue recurrentemente utilizada durante los años cuarenta y cincuenta como ejemplo de cine de calidad, por su reconocimiento en festivales internacionales, como los de Venecia y Cannes.

${ }^{5}$ En 1953 se diseñó un plan de reestructura de la industria, en un intento de recuperar las mermadas finanzas del Banco Nacional Cinematográfico y renovar a las distribuidoras únicas para cada mercado extranjero del cine mexicano (las empresas Películas Nacionales, para el mercado nacional, fundada en 1947; Películas Mexicanas, para el mercado latinoamericano, fundada en 1944; y Cinematográfica Exportadora, para Estados Unidos y Europa, fundada en 1954). Una buena descripción de este "Plan Garduño" está en GARCÍA RiERA, Historia documental del cine mexicano, t. 7, pp. 7-12. 
a los productores cinematográficos como accionistas de las distribuidoras que reorganizó o constituyó para comercializar las películas nacionales en México, Latinoamérica y el resto del mundo; estas distribuidoras concentraron el dinero fresco que se dirigía a la producción bajo el concepto de “anticipos” por las películas. La política del llamado "Plan Garduño” planteaba otorgar los anticipos más sustanciosos -hasta $85 \%$ del costo de la película- a las cintas consideradas de mayor "calidad artística". ${ }^{6}$

\section{A LA SOMBRA DE HOLLYWOOD}

La familia Calderón está ligada a la historia del cine mexicano desde sus orígenes. A partir de 1919 los hermanos Rafael y José Calderón Urrutia fueron exhibidores en varios salones del estado de Chihuahua y de la ciudad texana de El Paso. Al iniciar los años treinta crearon, en sociedad con Juan Salas Porras, la empresa Azteca Films Distributing Co., para distribuir títulos en español en Estados Unidos en tiempos en que el sonido restringió el consumo masivo del material hollywoodense entre la población de habla hispana. En poco tiempo, Azteca Films ya tenía presencia en los principales centros de población hispana, como Los Ángeles, Chicago y Nueva York. ${ }^{7}$

En la segunda mitad de los años treinta, el despunte taquillero del cine mexicano entre el público a ambos lados de la frontera impulsó a la segunda generación de los Calderón a incursionar en la producción. Pedro Calderón Stell, hijo de José Calderón, inició su carrera con la película La Zandunga (Fernando de Fuentes, 1937), con buenos resultados económicos. Pronto se uniría a esta vertiente del negocio Guillermo, hermano de Pedro.

${ }^{6}$ México Cinema (10 sep. 1955), citado por García Riera, Historia documental del cine mexicano, t. 8, p. 7.

7 "Hermanos y empresarios del cine", El Heraldo de Chibuabua (9 abr. 2009), consulta electrónica realizada el 9 de mayo de 2016 en: http://www.oem.com. $\mathrm{mx} / \mathrm{esto} /$ notas/n1117898.htm. 
El cine producido por los hermanos Calderón ${ }^{8}$ se caracterizó por su búsqueda de fórmulas genéricas taquilleras y de bajo costo, sostenidas en el carisma de "estrellas", varias veces descubiertas e impulsadas por ellos mismos. ${ }^{9}$ Su estrecho vínculo con el negocio de la exhibición les permitía tener el pulso del gusto del público popular, tanto en México como en el sector de inmigrantes mexicanos e hispanoamericanos en Estados Unidos.

La formación empresarial de la familia Calderón está ligada desde su origen a la tradición del cine de Hollywood. Los pioneros Rafael y José Calderón Urrutia crecieron en un entorno binacional: su origen social acomodado les permitió estudiar carreras comerciales en Nuevo México y posteriormente trabajar en la Kansas City Southern Railway Company; ${ }^{10}$ en ese entonces, Rafael tuvo su primer contacto con el cinematógrafo, en la Exposición Universal de Saint Louis, en 1904. Ya como exhibidores, proyectaban películas hollywoodenses y sus cines tenían la exclusividad en su territorio de producciones de la Universal y la Mutual Film. ${ }^{11}$

${ }^{8}$ Las películas producidas por los hermanos Pedro y Guillermo Calderón, juntos o por separado, fueron realizadas al amparo de varias compañías; las más prolongadas en el tiempo fueron Producciones Calderón, S. A., y Cinematográfica Calderón, S. A., que a finales de los años cuarenta y principios de los cincuenta se usaron indistintamente para la producción. En las actividades de las empresas también participó su hermano José Luis Calderón. Producciones Calderón dejó de producir a finales de los años cincuenta, mientras que Cinematográfica Calderón continuó activa hasta mediados de los noventa.

${ }^{9}$ Los casos más representativos de esta política fueron los de la mítica rumbera cubana Ninón Sevilla, su artista exclusiva desde los últimos años cuarenta y hasta su retiro a finales de los cincuenta, y Sasha Montenegro, la diva del "cine de ficheras" impulsado por Cinematográfica Calderón a partir de 1974.

10 "Hermanos y empresarios del cine", El Heraldo de Chibuabua (9 abr. 2009), consulta electrónica realizada el 9 de mayo de 2016 en: http://www.oem. com.mx/esto/notas/n1117898.htm.

"[...] don José vino al mundo el 30 de agosto de 1885 en San Andrés, Chihuahua, y don Rafael el 3 de abril de 1882 en la misma localidad."

11 Perdida (Viviana García Besné, 2011), documental, 15:14. 
La apuesta familiar por la producción se alimentó por la súbita demanda en sus salones de películas habladas en español, al iniciar los años treinta. Su búsqueda de un producto con sabor local, pero sin alejarse de las fórmulas narrativas y comerciales de Hollywood, se vio alentada por el triunfo taquillero en Estados Unidos de Allá en el Rancho Grande. "Este triunfo en particular provocó nuevas actividades comerciales del cine mexicano en Estados Unidos, en donde las empresas distribuidoras [como la Azteca Films] pronto establecieron múltiples sucursales: en San Antonio, El Paso y Nueva York y, por supuesto, Los Ángeles”. 12

Don José Calderón fue a la segura: reunió al artífice del triunfo de Rancho Grande, su director Fernando de Fuentes, con una "estrella" que combinaba su mexicanidad con la patente hollywoodense, la extiple Lupe Vélez, sin experiencia previa en el cine mexicano. La mera noticia de la contratación de Vélez impulsó una estrategia publicitaria que se prolongó durante su trayecto por tren hasta los estudios en México. ${ }^{13}$ Para su estreno, La Zandunga ya tenía garantizado un cómodo retorno de la inversión, lo que allanó el camino del proyecto fílmico de los Calderón, que no fue muy diferente del de toda la industria en ciernes del cine mexicano: cultivo de los géneros populares y canciones con los ritmos de moda. Su sello particular fue el énfasis en la selección de figuras femeninas atractivas y sus tramas aderezadas con detalles procaces, esto último en reto permanente a las restricciones de la censura. ${ }^{14}$

\footnotetext{
12 Castro Ricalde y McKee, El cine mexicano "se impone”, p. 30.

13 Perdida, 20:16.

14 En La Zandunga aparece un fugaz desnudo de María Luisa Zea al salir del río en que se baña, escena censurada, según García Besné, Perdida, 20:30. La siguiente película producida por los Calderón fue La posada sangrienta (Fernando Rivero, 1942), cinta de misterio protagonizada por Gloria Marín, como una chica ingenua rescatada de los peligros de un asesino por un detective perspicaz (David Silva); en una escena de énfasis chusco, Marín se sube a una escalera, mientras un turbado Silva no puede evitar mirarle las pantorrillas
} 


\section{DESARROLLISMO Y SENSUALIDAD}

En la segunda mitad de la década de 1940 se dio un fuerte impulso al desarrollo económico capitalista en México, mediante una inversión sostenida en infraestructura y en apoyo al crecimiento industrial, y a la consolidación de una élite empresarial nacional. La misma industria cinematográfica contó con un trato preferencial, por ejemplo, con la constitución, desde 1941, del Banco Cinematográfico. ${ }^{15}$ Esta política desarrollista se acompañó con un discurso que ensalzó la idea de progreso como un producto natural de las políticas diseñadas por el régimen. ${ }^{16}$ Progreso y desarrollo se conjuntaron para alimentar la identidad urbana de la ciudad de México, que triplicó su población entre 1930 y 1950, cuando superó los tres millones de habitantes. La transformación urbana y el crecimiento de los sectores medios se reflejaron en el cine nacional, por medio de comedias ubicadas en barrios populares de la ciudad, como La Merced o Peralvillo, y de melodramas que mostraban las supuestas aficiones -automóviles, abrigos de pieles, cabarets, cortejos a la orilla de la playa en Acapulco- y vicisitudes de la clase acomodada.

bajo su falda. Ese mismo año filmaron Noche de ronda (Ernesto Cortázar y Roberto Gavaldón), melodrama de alusiones prostibularias, amparado en el prestigio del músico Agustín Lara, autor del bolero homónimo, y reforzado por la presencia de la bailarina cubana María Antonieta Pons.

15 Costa, La 'apertura' cinematográfica, pp. 50-51, describe el "proceso de concentración de capitales" hasta la "formación de monopolios" en la producción, distribución y exhibición del cine en México durante la época. El Banco Cinematográfico tuvo reestructuraciones importantes en 1946-1947, que lo convirtieron en Banco Nacional Cinematográfico, y en 1953, véase nota 4.

16 "La marcha de México es definitiva. El futuro de nuestro país está en el corazón de todos sus hijos; por ello tenemos confianza en que la unidad nacional será inconmovible frente a cualquier problema que se nos presente y que sabremos con todo patriotismo buscar soluciones que satisfagan los intereses colectivos que garanticen los principios de la Revolución, nuestras libertades y el progreso del país”, dijo Miguel Alemán durante la lectura de su Informe del 1o de septiembre de 1950. Alemán VALdÉs, Informes presidenciales, p. 192. 
La maquinaria fílmica giró en torno de este juego de representaciones. Personajes exóticos y hasta cierto punto parias, como las rumberas o los padrotes, se hicieron ubicuos, pues permitieron representar los atractivos de la modernidad sin renunciar a la exaltación de una moralidad rígida y al empeño de alertar de los peligros de la pérdida de los valores tradicionales. La bulliciosa vida nocturna de la época, con su atmósfera de provocación moral, fue pretexto para una compleja e interesante representación para el consumo popular que buscaba, a un tiempo, preparar el terreno para los complejos procesos de modernización que estaban en curso y defender una idea de moralidad cada vez más endeble. ${ }^{17}$ Cualquier dosis de realismo o de crítica a la ideología hegemónica solía ser censurada, desde el guion, por el Estado, con el argumento genérico de evitar una “imagen denigrante” del país.

El "cine de rumberas”, un subgénero del melodrama con atmósfera cabaretil y música afrocaribeña, ofreció ventajas interesantes para los productores: favorecía el ánimo urbano celebratorio que impulsaba el discurso modernizador del régimen; ofrecía tramas truculentas con desenlaces complacientes y felices; presentaba mujeres de belleza exótica y ligereza de atuendos, y sobre todo no exigía inversiones cuantiosas y podía filmarse por completo en un estudio. Menor gasto y garantía de taquilla -tanto en México como en Latinoamérica, en procesos de modernización similares al caso mexicano- fue lo que encumbró a las rumberas entre 1946 y 1952 en el cine mexicano.

Pedro y Guillermo Calderón encontraron en las rumberas la cantera para consolidar y expandir su negocio de producción fílmica. Desde los títulos -Pervertida (1946), Carita de cielo (1946), Pecadora (1947), Coqueta (1949), Aventurera

17 Pulido, El mapa 'rojo' del pecado, presenta una acuciosa selección de relatos de la prensa del periodo que arroja luz sobre la construcción de personajes y estereotipos que también fueron representados en el cine de rumberas. 
(1949), Sensualidad (1950), Víctimas del pecado (1950), etc.-, sus películas dan cuenta del gozoso sensacionalismo intrínseco al género y muestran también su temprana especialización en temas vinculados a explotar la sexualidad hasta donde la censura lo permitiera. En 1953, sin embargo, hubo un viraje súbito: las rumberas prácticamente desaparecieron de las pantallas y a la visión truculenta y exaltadora de la ciudad le siguió una regresión moralista, defendida por una censura más férrea. ${ }^{18}$ Además, una crisis industrial contrajo la producción, encareció los costos, limitó el acceso al crédito del Banco Nacional Cinematográfico y condicionó todavía más las temáticas, por un lado, a los requerimientos de los exhibidores controlados por un monopolio, ${ }^{19} \mathrm{y}$

18 "Una clase media cada vez mayor y más fuerte exigía la erradicación -cuando menos aparente- del vicio y del pecado, y eso se reflejó en un cine cada vez más puritano, menos arrabalero"; GARcía Riera, Historia documental, t. 7, p. 156. Peredo, Cine y propaganda para Latinoamérica, pp. 442-444, considera también la influencia de Hollywood, que enfatizaba al iniciar la década de los cincuenta los valores religiosos mediante, por ejemplo, las superproducciones de temas bíblicos como una estrategia de propaganda anticomunista que permeó a toda Latinoamérica. Asimismo, la reforma de octubre de 1952 a la Ley de la Industria Cinematográfica de 1949 incluyó una restricción a la exportación de películas mexicanas: "No se autorizará la exportación de películas nacionales cuya exhibición en el extranjero se considere inconveniente por el tema y desarrollo de las mismas, aun cuando hayan sido autorizadas para exhibirse en territorio nacional" (Art. $2^{\circ}$, fracción X); la idea de perder el acceso a los mercados internacionales habría disuadido al grueso de los productores de insistir con los temas prostibularios. Finalmente, compárese con los códigos morales redactados por la Legión de la Decencia en esos años, glosados por Zermeño, "Cine, censura y moralidad en México", pp. 95-97, que alertaron sobre las "obras de ambiente sórdido en centros de vicio" y sobre el peligro de los "ritmos afrocubanos".

19 Para inicios de la década de 1950 los empresarios exhibidores William Jenkinks, Gabriel Alarcón y Manuel Espinosa Yglesias controlaban 80\% de las pantallas en México. Por medio de una hábil combinación de presión comercial al sector de la producción, apoyo tácito de los empresarios de Hollywood e influencia en las altas esferas políticas de México, el monopolio impuso sus criterios comerciales en favor del cine estadounidense y en detrimento del cine nacional. Una detallada descripción de esta guerra comercial por el cine 
por el otro, a las del régimen empecinado en mostrar una imagen positiva y épica de lo mexicano en el cine. Las nuevas reglas obligaron a los Calderón a buscar nuevas vetas para su producción: a su estrella Ninón Sevilla, por ejemplo, le construyeron tramas con más peso melodramático y menos alusiones a la prostitución, como Llévame en tus brazos (Julio Bracho, 1953), Amory pecado (Alfredo Crevenna, 1955) o Club de señoritas (Gilberto Martínez Solares, 1955).

Sin embargo, los Calderón no cejaron en su desafío a la censura en temas morales; al contrario, elevaron la apuesta. En 1955 produjeron su primera película con un desnudo parcial: La fuer$z$ a del deseo (Miguel M. Delgado), sobre un pintor atormentado por la pasión malsana que le inspira su modelo, interpretada por Ana Luisa Peluffo. Entre 1955 y 1956 filmaron, con la misma fórmula de desnudos inertes en melodramas moralistas: $E l$ seductor (Chano Urueta, 1955), La ilegítima (Urueta, 1955), La virtud desnuda (José Díaz Morales, 1955), Esposas infieles (Díaz Morales, 1955), La Diana cazadora (Tito Davison, 1956), la única filmada en colores, y Juventud desenfrenada (Díaz Morales, 1956). ${ }^{20}$

Otra respuesta a la crisis fue su incursión en el cine "de alta calidad artística”, con la expectativa de expandirse a nuevos

durante los años cuarenta y cincuenta se encuentra en Peredo, Cine y propaganda para Latinoamérica, pp. 400-458; PAXMAN, En busca del señor Jenkins, es una minuciosa biografía de William Jenkins que da cuenta del peso político del magnate y las redes de negocios que construyó desde finales del siglo XIX. 20 Los primeros desnudos en la producción fílmica nacional datan de los años treinta y fueron casos excepcionales. En 1933, La mujer del puerto (Arcady Boytler) mostró en forma fugaz los pechos desnudos de un personaje incidental; La mancha de sangre (Adolfo Best Maugard, 1937), por su parte, fue más audaz. En una secuencia muestra el baile de una prostituta desnuda, jugueteando con una vaporosa tela transparente; la audacia en este caso fue duramente castigada por la censura: la película no se exhibió sino hasta 1943 y, al parecer, sufrió mutilaciones por el Departamento de Supervisión Cinematográfica, GARcía Riera, Historia documental, t. 1, p. 289. 
mercados para seguir creciendo. El proyecto se llamó Sombra verde.

\section{MEXICAN EXOTICISM}

En abril de 1953 se estrenó en Estados Unidos la fantasía musical en colores Sombrero, de la Metro-Goldwyn-Mayer, filmada un año antes en México por Norman Foster, un viejo discípulo de Orson Welles que conocía bien el país, al grado que había dirigido cinco películas mexicanas durante la década anterior. ${ }^{21}$

Sombrero (titulada México de mis amores para su exhibición en el país) conjugó una visión caricaturesca de lo "mexicano" -Ricardo Montalbán usaba un estilizado atuendo charro y cantaba una versión en inglés de la popular canción Carta a Eufemia- y lo "latino", según la vieja tradición de Hollywood, una fórmula que solía gustar entre el público anglosajón y era vista con curiosidad por las audiencias latinoamericanas. Durante 1953 Norman Foster comenzó a preparar su siguiente proyecto: adaptar la novela Sombra verde, en colaboración con el español exiliado en México Luis Alcoriza, para aprovechar el éxito de su película previa y así retomar su carrera mexicana. La gran atracción era traer de vuelta al cine nacional a Ricardo Montalbán tras casi diez años de ausencia. ${ }^{22}$ Montalbán había concluido con Sombrero una larga exclusividad con MGM -compañía que lo impulsó como uno de los principales latin lover

${ }^{21}$ Para una descripción detallada del paso de Foster por el cine mexicano consúltese Ramírez, Norman Foster y los otros directores norteamericanos en México.

${ }^{22}$ Foster, Montalbán y Alcoriza tenían una prolongada amistad (Foster y Montalbán eran concuños, de hecho) y todos eran viejos conocidos de los Calderón. Foster dirigió a Montalbán en La fuga (1943), producción mexicana de José Luis Calderón, quien además fue productor ejecutivo de Nosotros (Fernando Rivero, 1944), protagonizada también por Montalbán. Por su parte, Luis Alcoriza inició su carrera de guionista con El abijado de la muerte (1946), con el apoyo y la guía de Foster en su última película mexicana. 
de la época- y buscaba diversificar su carrera para mantener su estatus de "estrella".

Para noviembre de 1953, Foster estaba en Cuernavaca enfrascado en la tarea del desarrollo del guion, ya con un acuerdo preliminar con Pedro y Guillermo Calderón. El proyecto tenía tiempo circulando para entonces: había una sinopsis y Alcoriza tenía materiales desarrollados para un guion no concretado para otros productores. Cuando cerraron el trato con los Calderón, Foster inició el trabajo por su cuenta, pues Alcoriza estaba en medio de la adaptación de El río y la muerte, con Luis Buñuel.

El primer tratamiento de la novela fue desarrollado por completo por Foster, procurando cierto sabor de Las minas del rey Salomón (1950) para "ganar más taquilla", ${ }^{23}$ y consultando opiniones de sus contactos en Estados Unidos para encontrar la fórmula más efectiva para agradar a ese público. ${ }^{24} \mathrm{El}$ resultado fue, según el mismo Foster, "suspenso, acción y belleza también". ${ }^{25}$

La original Sombra verde, escrita en 1949 por el abogado Ramiro Torres Septién, ${ }^{26}$ aportaba una trama algo confusa que descansa sobre la idea del enfrentamiento y posterior seducción del

23 'I'm trying to keep a sort of King Solomon's Mine flavour in the first part -as I think it is more taquilla", escribió Foster a Guillermo Calderón en carta del 26 de noviembre de 1953, Colección Calderón, PVAC. King's Solomon's fue la exitosa adaptación fílmica de la clásica novela de aventuras de $\mathrm{H}$. Rider Haggard (1885), donde un grupo de exploradores sajones pasan toda clase de vicisitudes en la sabana y la selva africanas.

${ }^{24}$ Uno de sus lectores fue el futuro productor Ray Stark, para entonces publicista y agente de talento, quien le dijo que la película debía cuidarse del exceso melodramático y rematar con un final feliz. "Ray Stark wrote me that we had read the synopsis and liked it -tought we should go easy on the melodrama. [...] He also wants a happy ending." Carta de Foster a Guillermo Calderón, 26 de noviembre de 1953, Colección Calderón, PVAC.

25 Carta de Foster a Guillermo Calderón, 26 de noviembre de 1953, Colección Calderón, PVAC.

${ }^{26}$ El guanajuatense Ramiro Torres Septién (1913-1978) publicó por lo menos cuatro novelas: Sombra verde (1949), Roquedal (1954), Noé nace cada día (1960) y Por la tierra muere el hombre (1975). 
"hombre de razón" por la "salvaje naturaleza". Algo anacrónica respecto de su evidente fuente de inspiración-Mansiones verdes (1904), de W. H. Hudson-,27 daba idea de la aclimatación que había alcanzado la idea liberal de progreso en el México del medio siglo.

La novela cuenta la historia de Federico, un ingeniero capitalino comisionado por su empresa para llevar dinero para el pago de trabajadores a la comunidad de Santiago Choápam, ubicada en una región remota de la sierra de Oaxaca, distante de la capital del estado "cuatro jornadas a caballo de ocho horas como mínimo cada una”. El hombre se obstina en internarse en los caminos por su cuenta, sólo con el apoyo de Pedro, un guía mixteco que no conoce bien la región serrana zapoteca; luego de recorrer varias comunidades y pasar penurias que provocan la queja de estar "en la salvaje y primitiva África enclavada en tierras mexicanas", terminan perdiéndose y Pedro muere por la picadura de una serpiente. Tras caer en una ladera, el malherido Federico es rescatado por Ignacio, un viejo bandido prófugo que se ha establecido en un claro de la selva con su joven hija Yáskara y un par de sirvientes indígenas. Recuperado poco a poco de sus heridas, Federico se enamora de la chica, debatiéndose entre el recuerdo de su amada y convencional esposa, Patricia, y la fuerza salvaje e inocente de Yáskara, que le pide que sea "su viejo".

27 En Mansiones verdes: “Abel, hijo de la aristocracia venezolana, obligado a huir de Caracas para salvar la vida tras tomar parte en un conato de revolución, relata su larga convivencia con los indios de la Guayana. Y, en particular, su alucinado amor por Rima, la mujer pájaro, una joven huérfana que ha crecido en el bosque hasta convertirse en una semidiosa a la que obedecen las serpientes y las corrientes de los ríos"; Edgardo Dobry, “Mansiones verdes, de W. H. Hudson", Letras Libres (mar. 2007). Norman Foster estaba preocupado por no concentrarse demasiado en la belleza selvática de los entornos, por el riesgo de parecerse demasiado al estilo narrativo de la novela de Hudson: "I think if we only have beauty - we get into Green Mansions and may fall in our faces". Carta de Foster a Guillermo Calderón, 26 de noviembre de 1953, Colección Calderón, PVAC. 
Una cuadrilla de rescate encuentra a Federico, quien es recibido casi como héroe en la ciudad. En un atropellado final, el ingeniero decide finalmente dejarlo todo y regresa a Oaxaca, sólo para descubrir que Ignacio está preso por su pasado fugitivo y Yáskara ha muerto. Arrepentido, Federico vuelve con su esposa. A su primera hija la bautiza como Patricia Yáskara. De narrativa torpe, racista y melodramática, Sombra verde exalta la figura del ingeniero como agente de progreso que, no obstante, redescubre en la naturaleza los valores morales que la civilización parece haber olvidado. El moralismo intrínseco al mensaje exige que el adulterio no se consume y, todavía más, que el prohibido objeto de deseo muera, para convertirse en simple símbolo de honestidad y vitalidad. ${ }^{28}$

\section{UNA PRODUCCIÓN ACCIDENTADA}

Los hermanos Calderón se comprometieron a financiar la elaboración, por parte de Foster y Alcoriza, de un guion en español y uno en inglés, para estar listos para una coproducción con una empresa estadounidense. En enero de 1954, Guillermo Calderón creía que podía cerrarse un trato con Republic Pictures, especializada en películas independientes, generalmente de bajo presupuesto. $^{29}$

${ }^{28}$ Sombra verde se inscribe en toda una tradición de novelas de tesis, carentes de valores literarios pero dotadas de pertinencia política, en una sociedad gobernada por un régimen empeñado en resaltar el progreso civilizatorio del país y las bondades del mestizaje y de los valores liberales. Otras muestras de esta corriente literaria son: Tierra de hombres (1946), de la guionista cinematográfica Elvira de la Mora; Muro blanco en roca negra (1951), del abogado y político Miguel Álvarez Acosta; El rebozo de Soledad (1951), del médico Xavier López Ferrer; y La mayordomía (1951), del abogado Rogelio Barriga Díaz, todas ellas adaptadas para el cine mexicano de la época.

${ }^{29}$ Carta de Guillermo Calderón a Alfonso Sánchez Tello, 7 de enero de 1954, Colección Calderón, PVAC. 
Foster firmó un convenio por 75000 pesos para escribir y dirigir la película tanto en inglés como en español. Con la sinopsis de 37 páginas en inglés bajo el brazo, Alfonso Sánchez Tello encabezó la búsqueda de inversionistas estadounidenses para participar en el proyecto. Su meta era conseguir 125000 dólares, más 40000 en caso de que los coproductores desearan la cinta en colores. ${ }^{30}$

Los problemas de la película comenzaron cuando la Sección de Directores -encabezada por Alejandro Galindo-, del poderoso Sindicato de Trabajadores de la Producción Cinematográfica (STPC), bloqueó la contratación de Norman Foster como director. El STPC tenía una rígida política restrictiva que prácticamente congeló la integración de nuevos directores desde 1945 y hasta los años setenta. ${ }^{31}$ No hubo forma de retirar el veto a Foster, pese a tener una filmografía mexicana previa que incluía éxitos taquilleros -como la segunda versión de Santa (1943), con Esther Fernández y Montalbán, o El abijado de la muerte (1946), con Jorge Negrete, el dirigente del sTPC fallecido apenas unos días antes de que Foster buscara el permiso para trabajar de nuevo en México. ${ }^{32}$

30 Memorándum interno de Producciones Calderón, fechado el 7 de enero de 1954, Colección Calderón, PVAC. En el mismo documento se especifica que Ricardo Montalbán recibiría 20\% de los ingresos generado por la versión en inglés de la película.

31 En 1945, al calor del triunfo político que significó la creación del Sindicato de Trabajadores de la Producción Cinematográfica, sus agremiados pactaron con la Asociación de Productores que tanto sindicato como productores impedirían el acceso a la dirección a cualquier nuevo elemento, exceptuando a los realizadores extranjeros de prestigio "que no vinieran a aprender, sino a enseñar". García Riera, Historia documental del cine mexicano, t. 3, p. 220. 32 "En vista del desarrollo de los acontecimientos detuvimos al señor Norman Foster pensando arreglar su asunto a través de [la sección sindical de] Técnicos y Manuales, cosa que nos ha sido imposible, por cuyo motivo el señor Norman Foster salió definitivamente para Los Ángeles el día de ayer". Carta de Guillermo Calderón a Azteca Films Inc., fechada el 12 de enero de 1954, Colección Calderón, PVAC. Jorge Negrete había fallecido el 5 de diciembre de 1953. 
El director sustituto de Foster fue Roberto Gavaldón, uno de los realizadores más reconocidos y respetados del momento -además de férreo defensor de la política sindical de puertas cerradas-, ${ }^{33}$ quien ya había firmado un contrato con Producciones Calderón el año anterior para filmar una película por definir. El encargo de Sombra verde fue lógico, dada la experiencia de Gavaldón, que incluía dos películas hollywoodenses con versiones en inglés y en español: Adventures of Casanova (1946) para la Eagle-Lion, y Littlest Outlaw (1953), recién filmada para Walt Disney. El cambio de director representó un gasto financiero importante: a Foster le pagaron 23100 pesos por la rescisión de su contrato, mientras que los honorarios de Gavaldón ascendieron a 80000 pesos. ${ }^{34}$

Para mediados de enero, Luis Alcoriza tenía listo el guion, que Gavaldón comenzó a revisar con el apoyo de José Revueltas, su colaborador habitual, para retomar el tema del final feliz y hacer la película más atractiva para el mercado estadounidense. A la par, se buscaba una protagonista femenina que sumara juventud, belleza y nombre estelar; para marzo se mencionaba a las francesas Françoise Arnoul y Cecile Aubry como posibles contrataciones, aunque muy pronto fueron descartadas. ${ }^{35}$ La contraparte de Montalbán sería Pedro Armendáriz, ya conocido por el público anglosajón por su participación frecuente en películas hollywoodenses, como Sangre de héroes (Fort Apache, John Ford, 1948), Tulsa (Stuart Heisler, 1949) y Rompiendo cadenas (We were strangers, John Huston, 1949). La preproducción marchaba con buen ritmo.

Mientras, Rubén Calderón -primo de Guillermo y Pedro, y directivo de la Azteca Films, la distribuidora familiar en

${ }_{33}$ Mino, La fatalidad urbana, pp. 38-42.

34 “Costo de la película 'Sombra verde' al 3 de julio de 1954”, memorándum interno de Producciones Calderón, Colección Calderón, PVAC.

${ }^{35}$ Carta de Isi Rosenfeld a Guillermo Calderón, 23 de febrero de 1954, Colección Calderón, PVAC. 
Estados Unidos- sostenía conversaciones con Leonard Goldstein, veterano productor de la Universal y de la 20th Century Fox que apenas en 1953 había formado su propia compañía. La propuesta era que Goldstein y sus socios invirtieran 75000 dólares (55000 en efectivo y 20000 en un crédito para procesos de laboratorio) a cambio de $50 \%$ de los derechos de la película en su explotación mundial de la cinta, excluyendo Latinoamérica. ${ }^{36}$

Esta negociación en ciernes seguramente aminoró el golpe que representó la súbita devaluación de la moneda mexicana frente al dólar, que pasó de costar 8.65 a 12.50 pesos, a partir de abril de 1954. En automático, los costos de producción aumentaron -el costo promedio de una película mexicana estándar se incrementó de 694000 a 750000 pesos-, ${ }^{37}$ en un mal momento para los Calderón, que ya tenían demasiado avanzados los preparativos y las expectativas de Sombra verde como para pensar en un recorte. La película arrancaría filmación de un momento a otro en locaciones de Veracruz, una vez que la Dirección General de Cinematografía autorizara el guion.

\section{LA CENSURA Y EL “INTERÉS NACIONAL”}

Los cines nacionales fueron, durante la primera mitad del siglo xx, un referente importante en la construcción de una identidad común. En ese sentido se convirtieron en herramientas no sólo de propaganda, sino de formación de las subjetividades, ${ }^{38}$

\footnotetext{
36 Academy of Motion Picture Arts and Sciences, "Leonard Goldstein Papers", recuperado el 9 de mayo de 2016 de: http://collections.oscars.org/link/ bio/128. La referencia a la negociación entre Rubén Calderón y Goldstein está en un memorándum interno de Producciones Calderón, sin fecha, Colección Calderón, PVAC.

37 García Riera, Historia documental del cine mexicano, t. 7, p. 153.

38 Zermeño, "Cine, censura y moralidad en México", pp. 77-78. De acuerdo con Zermeño, tanto la Iglesia como el Estado "han intentado afectar el curso de la formación de las subjetividades (formas de pensar y de corporeidad) en la sociedad mexicana del siglo xx [...], en principio, la cuestión de qué mensajes
} 
vigilados y guiados por los criterios impuestos por las élites política y religiosa desde sus respectivos espacios de poder. La consolidación del cine como entretenimiento de alcance masivo estuvo acompañada del desarrollo de mecanismos de censura, entendida como la prohibición de lo políticamente subversivo y lo moralmente inaceptable, que crearon espacios de acuerdo y de tensión entre el papel del cine como entretenimiento y su función formativa. ${ }^{39}$

El consenso censor entre dichas élites impuso a la industria cinematográfica los cauces desde los cuales crear un mercado de consumo cultural que reconociera la autoridad de las instituciones censoras, no siempre sin explorar subterfugios para ampliar los márgenes en la representación ${ }^{40} \mathrm{y}$, por ende, incrementar las posibilidades de lucro económico. La tensión entre el respeto a los lineamientos de la censura y la búsqueda de productos exitosos marcó las tendencias en la producción fílmica y, con

enviar o permitir difundir y cuáles evitar o prohibir, a través de [...] [los medios de comunicación] es una preocupación permanente de la élite que se siente como responsable de la formación y educación de las mayorías".

39 Montserrat Algarabel ha problematizado el concepto de censura cinematográfica para el caso mexicano. En "El poder de la mirada”, p. 165, resalta la evidente parcialidad desde donde la censura define lo subversivo o inmoral: "Ante la multiplicidad de opiniones en torno a la moralidad y a la inmoralidad, al igual que alrededor del carácter explosivo de lo que puede ser catalogado como subversivo, es que la censura pretende preservar una idea fija de lo que la sociedad es: la idea que se forma la institución censora de aquello en lo que consiste la estabilidad o la naturaleza propia de la sociedad. Y dicha idea es resultado de un particular proceso de semiosis, es decir, de atribución de significados”.

40 Cuando hablamos de "representación" nos referimos a las posibilidades narrativas del relato fílmico, es decir, las múltiples opciones de contar una historia, como explica Francesco Casetti en Teorías del cine: "Lo propio del filme de ficción es representar algo imaginario, una historia. Si se descompone el proceso, se puede ver que el cine de ficción es una doble representación: el decorado y los actores interpretan una situación que es la ficción, la historia contada; y la propia película, bajo la forma de imágenes yuxtapuestas, reproduce esta primera representación"; citado por AlgARABEL, "El poder de la mirada”, p. 169 (cursivas mías). 
los años, fue socavando los fundamentos morales sobre los que se construyó la idea de censurar el contenido de los filmes.

El primer reglamento de censura fílmica fue promulgado en 1919, bajo el gobierno de Venustiano Carranza, ${ }^{41}$ y estuvo vigente hasta septiembre de 1941, cuando se promulgó el Reglamento de Supervisión Cinematográfica, el cual estableció que cualquier película que pretendiera ser exhibida públicamente requeriría de la autorización de un Departamento de Supervisión Cinematográfica, el cual verificaría que los contenidos "estén de conformidad con lo dispuesto en el artículo $6^{\circ}$ de la Constitución". En la práctica, la falta de definición de criterios de censura implicó una aplicación discrecional por parte de la dependencia que, para finales de la década, ya generaba conflictos cotidianos con los productores nacionales. ${ }^{42}$

La imposición de una institución censora reflejó en gran medida el ejemplo estadounidense, donde desde 1930 se instituyó el código moralista creado por el sacerdote Daniel Lord a solicitud del presidente de la asociación de productores cinematográficos, William Hays, presionado por sectores conservadores, con la Iglesia católica a la cabeza, organizada por medio de la Legión

${ }^{41}$ El Reglamento de Censura Cinematográfica se promulgó el 1o de octubre de 1919. Uno de sus artículos establecía los criterios para representar a personajes de "profesión respetable": "si el villano es un político, abogado, sacerdote, maestro de escuela o miembro de otra profesión respetable, debe aparecer bajo aspecto noble". Citado por MERCADER, "La censura en el cine mexicano", p. 200.

${ }^{42}$ En septiembre de 1949, el jefe del Departamento de Supervisión, Guillermo Jiménez, aseguró: "El único criterio que puedo seguir es el que poseo: soy lector y sé cuándo se debe usar una medida...", Cinema Reporter (10 sep. 1949), citado por García Riera, Historia documental del cine mexicano, t. 5, p. 8. La declaración del censor se dio en medio de una disputa con la asociación de productores por la negativa de permiso de exhibición a 30 películas; ante la presión de los productores por la medida burocrática, "la solución inmediata que se le dio al conflicto fue la designación de una comisión especial que se encargará de supervisar las películas detenidas", en columna "Vida nacional", La Nación, núm. 418 (17 oct. 1949), p. 4. 
de la Decencia, su organización más activa en el tema. A partir de 1934 toda película rodada en Estados Unidos debía contar con la aprobación de la Production Code Administration, instancia de la misma industria cinematográfica que vigilaba desde los guiones la pertinencia, moral y política, de cada película. ${ }^{43}$

En 1934 comenzó a operar la Legión Mexicana de la Decencia, con un discurso similar sobre la promoción de un cine "moral debidamente censurado por personas competentes", ${ }^{44}$ tomando como ejemplo el Código Hays estadounidense. Si bien el reciente conflicto político entre la Iglesia católica y el gobierno mexicano dificultó el avance de la agenda censora de la Legión de la Decencia, para los años cuarenta el activismo católico consiguió introducir sus inquietudes morales dentro del paraguas abarcador de la política de "unidad nacional" promovida por el gobierno de Manuel Ávila Camacho. En el gobierno de Miguel Alemán Valdés, la coincidencia con la agenda católica se intensificó, como dejó claro el presidente desde el inicio de su administración cuando enfatizó su "decidida determinación de lograr la moralización pública”. ${ }^{45}$

${ }^{43}$ El complejo proceso de implementación del código de censura de Lord y Hays es desarrollado por BLACK, Hollywood censurado. William Hays fue presidente de la Motion Picture Producers and Distributors of America desde su creación en 1922 y hasta 1945.

${ }^{44}$ Zermeño, "Cine, censura y moralidad en México", p. 83, nota 8.

45 I Informe de Gobierno, 1o de septiembre de 1947, en Alemán Valdés, Informes presidenciales, p. 6. A lo largo de su sexenio (1946-1952), Alemán hizo alusión constante a la "moralidad pública", en principio ligada a la persecución de la corrupción de los funcionarios; sin embargo, pronto extendió el énfasis retórico al conjunto de la sociedad: "Llegada la Revolución a su madurez, garantizadas todas las libertades y consagrados todos los derechos por la Constitución Política que nos rige, debemos, todos los mexicanos, dedicarnos a producir lo necesario para la satisfacción de las necesidades vitales; a sujetar nuestra conducta a las normas morales; a templar nuestra decisión ante las circunstancias adversas, y a fortalecer nuestra nacionalidad y nuestras instituciones, trabajando sin descanso y poniendo una inquebrantable fe en nosotros mismos; en la conciencia de que, los destinos de las generaciones que 
En 1949, con la promulgación de una nueva ley cinematográfica y la creación de la Dirección General de Cinematografía, ${ }^{46}$ se profesionalizó la censura -llamada oficialmente "supervisión"y se adoptaron criterios que sugieren un acuerdo entre la élite política y la religiosa respecto de la noción de censura, socialmente presentada como un medio por el cual se preserva el proyecto de nación..$^{47}$ En el reglamento, promulgado el 6 de agosto de 1951, se estableció por primera vez un código que pretendió clarificar los lineamientos de censura, integrando plenamente las preocupaciones políticas con las morales. Las prohibiciones expresas se ordenaron en cuatro grandes rubros: 1) ataques a la

nos sucederán, están en nuestras manos. De lo que ahora hagamos, depende el mañana de la patria", II Informe de Gobierno, 1o de septiembre de 1948, en Alemán Valdés, Informes presidenciales, p. 90 (las cursivas son mías).

${ }^{46}$ Desde 1941 el gobierno mexicano había catalogado al cine como industria nacional estratégica, lo que implicaba una supervisión permanente de sus contenidos, acompañada de una política de financiamiento por medio de un Banco Cinematográfico (fundado en 1942), entidad financiera de carácter mixto dedicada a la inversión exclusiva en este sector. En 1947 se constituyó la Comisión Nacional de Cinematografía, encargada de fomentar la producción de cine de “interés nacional" para el Estado (además, en ese año el Banco Cinematográfico se convirtió en Banco Nacional Cinematográfico, con una participación y un control estatal mayor); en 1949 se estableció la Dirección General de Cinematografía, dependiente de la Secretaría de Gobernación, que fue la oficina encargada de supervisar, y autorizar, modificar o de plano prohibir, los guiones de las películas que solicitaban crédito al Banco Nacional Cinematográfico; una vez filmadas, tenía la potestad de autorizar, o no, su exhibición. Peredo, Cine y propaganda para Latinoamérica, pp. 365-367.

47 Zermeño sugiere, a partir de su revisión de los documentos de la Acción Católica y la Legión Mexicana de la Decencia, que durante los años del alemanismo y el ruizcortinismo (1946-1958) hay una influencia importante de los postulados morales de la Legión Mexicana de la Decencia (LMD) sobre los criterios de la censura de la Dirección General de Cinematografía; en esos años, la LMD redactó (o recibió) un Código de Producción Cinematográfica, fuertemente inspirado en el Código Hays. Zermeño, "Cine, censura y moralidad en México”, p. 87. Por su parte, Laura Pérez Rosales ha documentado un acercamiento directo entre la Dirección General de Cinematografía y la LMD, a partir de 1953, para colaborar en temas de censura. "Censura y control”, pp. 107-108. 
vida privada, 2) ataques a la moral, 3) provocación o apología de delitos o vicios, y 4) ataques al orden y a la paz públicos. ${ }^{48}$

En el caso de Sombra verde, la rutinaria "supervisión" de la Dirección de Cinematografía objetó una secuencia completa, en la que un anciano ofrece a Federico, de paso en una comunidad llamada San Miguel, a “dos inditas de no más de quince años”49 para tener relaciones sexuales; éste se niega y por ello es perseguido por los hombres de la comunidad: según sus costumbres los forasteros deben tener sexo con sus mujeres jóvenes para embarazarlas y dar sangre nueva a la comunidad para ayudarla a liberarse de la epidemia de vitiligo o mal del pinto. La persecución provoca que Federico y Pedro se pierdan en la selva. Las observaciones al guion indican:

La escena que se inicia en la toma 111 página 22, es francamente desechable, pues las costumbres, un tanto primitivas, de los pueblos indígenas, que pudieron ser vigentes en otros tiempos, ahora ya no lo son y aunque así lo fueran degradan al país, sobre todo cuando las películas salen al extranjero, pero además hacen muy mal efecto en las mentes sencillas de la gente del pueblo que son quienes más disfrutan con las historias románticas y melodramáticas. Esta escena que termina en la toma 128 página 24, deberá ser suprimida y cambiada por otra en donde los indígenas planteen su desconfianza ante los forasteros que tratan de explotar el barbasco, porque crean que les van a quitar sus tierras. [...] Se buscará la forma de rehuir las escenas que pinten la suciedad y la miseria en la forma en que se

${ }^{48}$ Cada rubro fue definido, sin librar la ambigüedad, en los artículos 70, 71, 72 y 73 del reglamento; Diario Oficial (6 ago. 1951), p. 12. Por ejemplo, los "ataques a la moral" se definieron como los "actos licenciosos o impúdicos" según "el concepto público"; y entre los "ataques al orden y a la paz públicas" se ubicó a las "injurias a la Nación Mexicana o a las entidades políticas que la forman".

${ }^{49}$ La frase es de Torres Septién (1949), Sombra verde, p. 24. Este pasaje es ilustrativo del racismo que permea toda la novela. 
hace en la toma 99 página 20, sin dejar de enseñar la forma primitiva en que los indígenas viven, porque en la otra, también se denigra a México. ${ }^{50}$

La revisión de Gobernación, pese a los cortes impuestos, consideró que la película "puede ser aprovechada para enseñar las riquezas que envuelven las selvas mexicanas, las bellezas de sus parajes y las costumbres interesantes de los indígenas [...], pero rehuyendo todos los aspectos que denigren al país". ${ }^{1}$ Mediante este tipo de diagnósticos, la Dirección de Cinematografía imponía la idea de nación que procuraba construir el régimen y fortalecía la certeza, ya familiar para toda la industria fílmica, de que las películas, además de entretener, debían aleccionar a las “mentes sencillas de la gente del pueblo" sobre las maneras de superar las formas "primitivas" de vida e integrarse al proyecto de desarrollo nacional. ${ }^{52} \mathrm{El}$ visto bueno abriría la llave de un generoso financiamiento estatal, que en conjunto sumó más de 900000 pesos.

\section{UN NEGOCIO FRUSTRADO}

A mediados de mayo arrancó el rodaje de Sombra verde en las zonas de Poza Rica y de Catemaco, en Veracruz, con un cambio importante: Pedro Armendáriz no estuvo disponible para las fechas de filmación, así que fue sustituido por Víctor Parra como Ignacio, el padre de Yáskara. El papel femenino recayó finalmente en Ariadna Welter, bella actriz con poca experiencia, pero reconocida por ser hermana de la estrella hollywoodense Linda Christian, esposa de Tyrone Power. El guía

50 Secretaría de Gobernación, "Sombra verde, observaciones al guion técnico”, 1o de junio de 1954, p. 6 (las cursivas son mías). Colección Calderón, PVAC. La secuencia, como solicitó Gobernación, no se filmó.

51 Secretaría de Gobernación, "Sombra verde, observaciones al guion técnico”, 1o de junio de 1954 , p. 7.

52 Véase Zermeño, “Cine, censura y moralidad en México”, p. 89. 
indígena del protagonista fue interpretado por el competente actor principiante Jorge Martínez de Hoyos.

La filmación en la locación marchó sin complicaciones mayores, aunque se prolongó más de lo habitual. Una nota publicitaria reproducida por el diario La prensa, de San Antonio, Texas, da un tono más épico al rodaje:

Ricardo [Montalbán] tuvo una escena en la que aparece con un puma salvaje, completamente solo, dentro de una empalizada en la que su única defensa era un revólver, que solamente podía usar en caso extremo, ya que en la película no entra su uso. Y el actor rechazó enérgicamente el uso de un "doble”, e hizo la escena completa, manteniéndose alerta, pero siempre dentro de lo ordenado por el argumento de la cinta. Después de filmada esta escena y ya salido Montalbán de la empalizada, el puma escapó y estuvo dos días en el monte, causando la muerte de dos vacas, hasta que fue cazado.

Y esto fue solo el principio. Ricardo Montalbán se tiró a un precipicio rodando más de seis metros, hasta una red, causándose heridas en el cuerpo, pero siempre rechazando con firmeza el ser doblado por otra persona. Dos días más tarde hacía otra escena en la que va atravesando la selva y es atacado por zopilotes, fue picado por un alacrán, y le fue aplicado un antídoto y a pesar de la insistencia de [Guillermo] Calderón y de Roberto Gavaldón, de que viniera a México a hacerse ver por un médico, no quiso interrumpir la filmación. Afortunadamente el piquete no tuvo consecuencias fatales, ya que el antídoto fue aplicado a tiempo. Pero las dificultades no terminaron ahí para el héroe de "Sombra verde", que lo viene a ser también fuera de la película; más tarde, hubo otra escena en la que tenía que detener a varios caballos en huida, lo que también le ocasionó serios golpes..$^{53}$

53 “'Sombra verde' una cinta de peligros en su filmación”, nota sin autor, en La prensa, San Antonio Texas (10 jul. 1954). La nota da como fuente de la información del rodaje al productor Guillermo Calderón. 
La escena del puma es mucho más discreta de lo que el testimonio haría suponer. Apenas un encuadre muestra a Montalbán empuñando una pistola en un claro de la selva y a unos metros pasa un pequeño puma. El resto de la escena se resuelve con intercortes a una imagen de stock. Más espectacular resulta una secuencia filmada en la cascada de Eyipantla, en la selva de Catemaco, Veracruz: el cansado Federico atraviesa un puente colgante sobre un río caudaloso y con fuerte corriente que metros adelante se transforma en una cascada; Ignacio rompe la cuerda que sostiene el puente y Federico cae con los dos caballos que va guiando (en uno va el cadáver de su guía indígena). Federico nada en medio de la fuerte corriente mientras que los dos caballos son arrastrados hasta caer al precipicio. La escena muestra con crudeza el sacrificio de los animales.

La filmación continuó en los estudios San Ángel, al sur de la ciudad de México, y concluyó en julio, sumando casi ocho semanas de trabajo. Mientras filmaban se avanzaba en la idea de modificar el guion para darle un final feliz a la película. Según el argumento original, Federico es encontrado por una patrulla de rescate, entonces:

Federico lucha entre su amor y su deber y al fin decide regresar al lado de su esposa, Yáskara lo insta en todas las formas a quedarse en El Paraíso [la finca donde Ignacio la ha criado, lejos de la civilización], cuando él se aleja, la joven sube entre peñascos para gritarle y tratar de detenerlo, sin que ella pueda evitarlo, se despeña cayendo a un profundo barranco, de donde es recogida por Federico y su padre, solo para expirar en los brazos de su amado. Federico, después de darle sepultura a la joven, regresa a su mundo. ${ }^{54}$

\footnotetext{
${ }^{54}$ Secretaría de Gobernación, "Sombra verde, observaciones al guion técnico", 1 o de junio de 1954, pp. 5-6, documento citado.
} 
Se encargó la redacción del final a José Revueltas, quien propuso dos opciones para lograr "un Happy Ending americano", que salvara el requisito moral de no consumar un adulterio. En la primera, los soldados que buscan a Federico le anuncian que Patricia, su esposa, ha muerto "en la ciudad, de congestión cardiaca o de cólico miserere [...], Federico así no tendría ningún remordimiento puesto que desde el momento en que se extravío en la selva fue un títere llevado por la fatalidad"; Revueltas pone sus reservas a esta opción argumental: "a mí no me gusta este final, pero cosas más absurdas e inesperadas hemos visto en buenas películas para llegar a un final feliz”. En la segunda opción, Federico niega su identidad a los soldados que lo buscan y se queda en El Paraíso; al justificar su decisión frente a Ignacio, Federico le dice que lo que siente por Yáskara ha borrado el cariño que sentía por Patricia, pero sobre todo, al contactar con la naturaleza y con el amor de la joven, había sentido por primera vez en su vida la presencia de Dios: “se quedará con Yáskara porque al quererla con todo su corazón siente que Dios le ha marcado ese camino". 55

Ninguna de las dos opciones se materializó; quizá implicaban el desarrollo de escenas adicionales que elevarían más los gastos de la cinta. Pero la película sí gozó de un final abierto, conseguido en la mesa de edición. Revueltas proponía que el

55 "Sugestiones para un final amable de 'Sombra verde", mecanuscrito sin fecha ni autor, Colección Calderón, PVAC. A partir de la revisión del estilo narrativo y temático del documento considero que el autor es José Revueltas. El crédito de Revueltas fue eliminado de la película (y se integró, quizá por error, un crédito para Rafael García Travesí como autor de diálogos adicionales), sin que haya constancia de los motivos. Una queja ante la Sección de Autores y Adaptadores de la STPC derivó en un oficio del 11 de enero de 1955 (unos días después del estreno en México) dirigido a Producciones Calderón, en que se establece que los créditos de la cinta deben aparecer "a favor de los $\mathrm{C}$. C. Roberto Gavaldón, Luis Alcoriza y José Revueltas”, Colección Calderón, PVAC. En la copia que se conoce hoy en día de la película no está subsanado el error. 
principal escollo para llegar al final feliz era la presencia de $\mathrm{Pa}$ tricia, quien aparecía en una secuencia al principio de la cinta, que finalmente desapareció en el montaje; se convirtió en una referencia y un rostro en una fotografía. Al final, Yáskara sí sube a los peñascos mientras Federico parte con los soldados, pero cuando está a punto de saltar al vacío, duda, y la voz en off de su padre la consuela: "Yáskara, déjalo que se vaya, pero si te quiere de veras, volverá. Que regrese a su mundo, que viva otra vez en el ambiente en que siempre ha vivido. Si descubre que todo aquello era una mentira, volverá, tenlo por seguro, y entonces sí será amor de verdad".

El final abierto planteaba una arriesgada apuesta moral, pues complementaba una escena romántica y erótica muy lograda. Federico se baña en una laguna, se rasura mientras Yáskara lo mira, sentada frente a él en la orilla, con las piernas abiertas y apenas cubierta por un delgado y corto vestido. Ahí le propone que sea "su viejo", pues ambos son fuertes, "somos como lobo y loba", le dice al hombre que no parece tomarla en serio. Luego la chica se arroja al agua y emerge frente a la cámara dejando ver sus pezones bajo el vestido mojado. Ahí le muestra a Federico un par de figuras de barro, "este eres tú y esta soy yo", dice mientras junta y restriega las figuritas, antes de que el hombre la bese apasionadamente. ${ }^{56}$

Para los últimos días del rodaje el costo de la película ascendía ya a 1826656.96 pesos, ${ }^{57}$ más del doble del costo promedio de las cintas nacionales producidas en ese año. El financiamiento se

56 No hay una referencia explícita a una cópula, pero sí una sugerencia, plenamente asumida por el guion; el Departamento de Supervisión, por otro lado, había dejado claro en su dictamen que la película estaba autorizada para adultos. En la copia de la película que actualmente es visible está mutilada esta escena.

57 “Costo de la película 'Sombra verde' al 3 de julio de 1954." El costo era equivalente a un poco más de 146000 dólares, según el tipo de cambio del momento. 
hizo a partir del crédito del Banco Nacional Cinematográfico y de los anticipos de las distribuidoras -que en conjunto cubrieron 944563 pesos, $52 \%$ del total de la producción- pero también exigió recurrir a préstamos para cubrir el gasto extraordinario..$^{58}$

La expectativa era que la venta de los derechos de exhibición a un inversionista estadounidense permitiría recuperar y generar ganancias. Para principios de julio, Guillermo Calderón había encargado a Sara López Figueroa la traducción de los diálogos de la película para el doblaje, ${ }^{59}$ al parecer estaba seguro de cerrar pronto el negocio. Las pláticas con Goldstein Productions, sin embargo, no avanzaban y se interrumpieron cuando Leonard Goldstein murió sorpresivamente el 23 de julio. Un día antes, el 22 de julio, Guillermo Calderón envió una carta al productor de la United Artists, Arnold Picker, de visita en México, para proponerle que viera la película. ${ }^{60}$

En septiembre, Pedro Calderón viajó a Los Ángeles para mostrar Sombra verde. En un memorándum, dirigido a sus hermanos José Luis y Guillermo, cuenta que la cinta se exhibió en funciones por separado a Kenneth McKenna, de MGM; Robert Goldstein, hermano del fallecido Leonard; Bob Jacks, de 20th

58 “Costo de la película 'Sombra verde' al 3 de julio de 1954." El total de la inversión se completó con varios "préstamos a corto plazo", entre otros, de Valentín Azpro, Eduardo Quevedo, Emilio Hamui, los hermanos Abularach, Ninón Sevilla y el mismo Ricardo Montalbán. Las inversiones mayores, sin embargo, correspondieron al Banco Nacional Cinematográfico -que invirtió 200000 pesos, más 150000 "de anticipo"-y a la distribuidora Películas Mexicanas, que anticipó 457765 pesos por su futura exhibición en Centro, Sudamérica y el Caribe, además de invertir 136798.50 pesos.

${ }^{59}$ Carta de Sara López Figueroa de Morales a Guillermo Calderón, 12 de julio de 1954, Colección Calderón, PVAC. Sara López era la traductora de B. Traven y tenía amplios vínculos con la comunidad cinematográfica, en gran medida porque Gabriel Figueroa era su primo. Los diálogos en inglés quedaron listos un mes después de concluida la filmación, dato que confirma que la proyectada filmación paralela en inglés no se realizó.

${ }_{60}$ Carta de Guillermo Calderón a Arnold Picker, 22 de julio de 1954. Colección Calderón, PVAC. 
Century Fox; y a Robert F. Blumofe, de United Artists. Todos respondieron vaguedades sobre la buena factura de la película y remitieron a Calderón a las oficinas de Nueva York para cualquier gestión. El más honesto fue Goldstein, quien le dijo que consideraba "difícil que una Major Company se pueda interesar por ella”. Pedro Calderón no tenía ya muchas esperanzas: "Desde luego Sombra verde no se enseña más a nadie aquí en Hollywood, porque es perder el tiempo inútilmente y sólo resta el último recurso que es ir derechito al 'grano' o sea New York, pues no podemos ni debemos perder el tiempo en ilusiones que solo conducen a pérdida de dinero". ${ }^{61}$

Sin dinero fresco, los Calderón decidieron estrenar en México el 23 de diciembre, con buen éxito de público (duró seis semanas en su sala de estreno, el Palacio Chino); en la publicidad de la película alardearon con el costo de producción: “ ¡ $\mathrm{La}$ primera película mexicana, que por su costo y calidad, coloca a nuestro cine a la altura del mejor del mundo!". ${ }^{62}$ En los días previos y posteriores al lanzamiento se realizó una campaña de publicidad que incluyó la cobertura periodística de una supuesta amenaza de demanda de Ariadna Welter para que cortaran la secuencia en la que se distinguen sus pechos desnudos. El columnista Jorge Mendoza Carrasco Lumière describía así el "conflicto":

La joven actriz Ariadna Welter (la que armó un escandalito hace días porque Guillermo Calderón no quiso suprimir de Sombra verde una escena en la cual se le ve casi desnuda) está dudando entre proceder judicialmente contra aquel productor o llevar el asunto a la Asociación de Actores para que sea esta entidad la que saque adelante el debatido asunto [...] Aunque a lo mejor no hace nada

${ }^{61}$ Memorándum de Pedro Calderón dirigido a José Luis Calderón, septiembre 27 de 1954, Colección Calderón, PVAC.

62 Anuncio publicitario, Excelsior (jueves 23 dic. 1954), p. 4-B. 
por miedo a que los demás productores le tomen miedo y no la contraten en lo sucesivo. ${ }^{63}$

El énfasis en el desnudo de Welter -la foto fija de la escena del lago fue la elegida para los carteles promocionales en los periódicos-fue sin duda una estrategia comercial coherente con la especialización de los hermanos Calderón en la explotación de la sexualidad como imán taquillero.

El éxito nacional dio respiro a las tribulaciones financieras en torno de Sombra verde. A lo largo de todo el año siguiente se buscó colocar la cinta entre potenciales compradores. Para mediados de 1955 no había avances, así que se exhibió en Estados Unidos en el circuito cubierto por la distribución de la Azteca Films, con buenos resultados. En Los Ángeles se estrenó en forma simultánea en los teatros Million Dollar y Maya, los dos más importantes para las películas en español en esa ciudad. ${ }^{64}$

\section{DESENCANTO Y NUEVOS CAMINOS}

La sentencia de Goldstein fue certera: ninguna major hollywoodense se interesó por Sombra verde, a pesar del nombre de Ricardo Montalbán. Sin embargo, el doblaje de la cinta sí se realizó, al parecer a finales de 1955 o principios de $1956 .{ }^{65}$ La cinta se vendió para Argentina, Francia e incluso Japón, Birmania, Pakistán

${ }^{63}$ Lumière, “¡Cámara!”, columna en Excelsior (miércoles 29 dic. 1954), p. 4-B. Mendoza Carrasco tenía fama de que "cobraba las menciones a personajes consignados en su columna", según Vicente Leñero, "En el Excelsior de Rodrigo de Llano", columna "Lo que sea de cada quien", Revista de la Universidad de México, núm. 116, octubre de 2013, versión electrónica recuperada el 9 de mayo de 2016 de: http://www.revistadelauniversidad.unam.mx/articulo.php ?publicacion $=83 \&$ art $=2371 \& \sec =$ Columnistas

64 "Montalbán de nuevo en el cine mexicano", nota sin autor Notas de Kingsville, Kingsville, Texas (28 jul. 1955), p. 2.

${ }^{65}$ Armando del Moral, en su columna "De visita con las estrellas", La prensa, de San Antonio, Texas (9 dic. 1955), escribe: "Ricardo Montalbán [...] saldrá 
y Ceilán. ${ }^{66} \mathrm{Y}$ también lograron, finalmente, colocarla con un inversionista estadounidense, un hombre curiosamente afín al tipo de cine en el que los Calderón comenzaban a encasillarse.

Walter Bibo era un distribuidor de películas clase B. Por medio de su empresa, llamada Excelsior Pictures, había colocado en el mercado estadounidense cintas diversas, como la adaptación fílmica italiana de la ópera El barbero de Sevilla (Mario Costa, 1947). En 1954 tuvo su mayor momento de celebridad cuando produjo Garden of Eden, pionero filme nudista dirigido por el alemán Max Nosseck; al año siguiente, el estado de Nueva York prohibió la exhibición de la película y el caso llegó hasta la Corte de Apelaciones del Estado de Nueva York. El fallo del juez transformó el futuro del cine de bajo presupuesto: se dictaminó que mostrar desnudos no implica, por sí mismo, obscenidad. ${ }^{67}$ Un nuevo mercado fílmico estaba abierto. Ahí comenzó su carrera americana Sombra verde, renombrada Untouched, finalmente doblada al inglés y promocionada como una producción de Excelsior Pictures Corp.

Los Calderón voltearon la página. No volverían a probar suerte con películas costosas o de "alta calidad" -demasiado complicadas para vender, con márgenes de ganancia más estrechos y con un mayor escrutinio gubernamental-. Por

en estos días para Nueva York con el fin de doblar al inglés su película Sombra verde, que hizo en español en México”.

66 Carta de Argentina Sono Films a Guillermo Calderón, 5 de mayo de 1955, Colección Calderón PVAC. En una nota titulada "El cine azteca gusta mucho a los japoneses”, de Notas de Kingsville, Kingsville, Texas (8 sep. 1955), p. 2, se reproducen declaraciones de Pedro Calderón sobre los mercados de Asia a donde había enviado la película. En Francia se exhibió con el título La belle de Vera Cruz.

67 Lewis, Hollywood v. Hard Core, p. 200. La película cuenta la historia de una familia en conflicto que, por una avería mecánica, debe quedarse unos días en una comunidad nudista, lugar donde redescubren los lazos que los unen; una trama insulsa para que la cámara mostrase a familias tomando el sol, jugando voleibol o nadando desnudas, cuidándose de no mostrar genitales. 
el momento prefirieron concentrarse en la moda del voyerismo moralizante, inspirado en Garden of Eden, con películas como la ya citada La virtud desnuda. No continuaron con el lucrativo subgénero porque la Dirección de Cinematografía apretó sus criterios censores y prohibió los desnudos. ${ }^{68}$

La experiencia de Sombra verde, fallida para los Calderón -pese a sus buenos resultados de taquilla, e incluso de crítica- ${ }^{69}$ muestra algunos de los obstáculos que afrontaron los productores cinematográficos mexicanos en sus afanes de sortear la crisis durante los años cincuenta: el control cada vez más coordinado de la censura de la Dirección de Cinematografía, vinculado al financiamiento de las producciones fílmicas; los escollos sindicales, que imposibilitaron innovar en visiones autorales distintas a las de los directores ya establecidos; la presión de los exhibidores, tanto el monopolio nacional como los mercados internacionales, para contar con materiales populares muy específicos; y la inercia del negocio y el realismo financiero, que impulsaban a explotar lo probado, generando las ganancias más altas posibles con los menores inversión y esfuerzo. El resultado fue un cine generalmente rutinario, lejos de "ilusiones que sólo conducen a pérdida de dinero", y marcado por una moralidad estándar funcional con el objeto de influir en la formación de la

${ }^{68}$ García Riera, Historia documental del cine mexicano, t. 8, p. 170.

${ }^{69}$ Por ejemplo, el escritor Rafael Solana alabó la película en su columna de reseñas cinematográficas de Excelsior. Consideró que su director, Roberto Gavaldón, "se reafirma en esta cinta como el mejor, hoy, de los directores del cine mexicano", y concluye que Sombra verde es "una gran película, de lo mejor del año, y tiene grandes momentos en que puede compararse con lo mejor del cine universal". Columna "La película de anoche", Excelsior (miércoles 29 dic. 1954), p. 5-B. La valoración fue ratificada el año siguiente por la Academia Mexicana de Ciencias y Artes Cinematográficas, que en su décima edición nominó en cuatro ternas a Sombra verde: mejor película, dirección, fotografía (Alex Phillips) y actor secundario (Jorge Martínez de Hoyos); en las últimas dos categorías resultó ganadora. Fue, por cierto, la única película que los Calderón, en sus 60 años en el cine, lograron colocar en la terna de mejor película de los premios Ariel. 
subjetividad de los espectadores, aportándoles una visión de la realidad en sintonía con los principios ideológicos del régimen y de sus aliados -como la Iglesia católica-. Este cine, institucionalizado y en crisis, no tardaría muchos años en resquebrajarse.

\section{SIGLAS Y REFERENCIAS}

PVAC Permanencia Voluntaria Archivo Cinematográfico, Colección Calderón. Carpeta de producción de Sombra verde, 19531955.

Algarabel, Montserrat, "El poder de la mirada: un análisis comparado de películas censuradas y censurables", en Fernando Aguayo y Lourdes Roca (coords.), Imágenes e investigación social, México, Instituto Mora, 2005.

Alemán Valdés, Miguel, Informes presidenciales, México, Centro de Documentación, Investigación y Análisis, Cámara de Diputados, LX Legislatura, 2006.

Aurrecoechea, Juan Manuel, "Figueroa, educador visual (Donde se describen los esfuerzos del cinefotógrafo de los cielos de México en la difusión de instructivos para el barrido higiénico de alfombras y otros materiales educativos de importancia estratégica)", en Luna Córnea, 32 (2008), pp. 115-125.

Black, Gregory, Hollywood censurado, Madrid, Akal, 2012.

Castro Ricalde, Maricruz y Robert McKee, El cine mexicano "se impone", México, Dirección de Literatura, Universidad Nacional Autónoma de México, 2011.

Costa, Paola, La 'apertura' cinematográfica, Puebla, Universidad Autónoma de Puebla, 1988.

Dobry, Edgardo, “Mansiones verdes, de W. H. Hudson”, en Letras Libres, 66 (mar. 2007). https://www.letraslibres.com/mexico-espana/libros/mansionesverdes-wh-hudson. Consultado el 10 de noviembre de 2017.

García Riera, Emilio, Historia documental del cine mexicano, México, Universidad de Guadalajara, Consejo Nacional para la Cultura y las Artes, Secretaría de Cultura del Gobierno del Estado de Jalisco e Instituto Mexicano de Cinematografía, 1992. 
García Riera, Emilio, Historia documental del cine mexicano, México, Universidad de Guadalajara, Consejo Nacional para la Cultura y las Artes, Secretaría de Cultura del Gobierno del Estado de Jalisco e Instituto Mexicano de Cinematografía, 1993, t. 5.

García Riera, Emilio, Historia documental del cine mexicano, México, Universidad de Guadalajara, Consejo Nacional para la Cultura y las Artes, Secretaría de Cultura del Gobierno del Estado de Jalisco e Instituto Mexicano de Cinematografía, 1993, t. 7.

García Riera, Emilio, Historia documental del cine mexicano, México, Universidad de Guadalajara, Consejo Nacional para la Cultura y las Artes, Secretaría de Cultura del Gobierno del Estado de Jalisco e Instituto Mexicano de Cinematografía, 1993, t. 8.

García Riera, Emilio, Breve historia del cine mexicano, primer siglo 18971997, México, Ediciones Mapa, Consejo Nacional para la Cultura y las Artes, 1998.

LeÑERo, Vicente, "En el Excelsior de Rodrigo de Llano", columna "Lo que sea de cada quien", en Revista de la Universidad de México, 116 (oct. 2013). http:// www.revistadelauniversidad.unam. $\mathrm{mx} /$ articulo.php?publicacion=83\&art=237 $1 \& s e c=$ Columnistas. Consultada el 10 de noviembre de 2017.

Lewis, Jon, Hollywood v. Hard Core: How the Struggle Over Censorship Saved the Modern Film Industry, Nueva York, New York University Press, 2000.

Magdaleno, María de los Ángeles, "Bucareli 113. Los orígenes de la censura en México”, en Estudios Cinematográficos, 34 (oct. 2011-mar. 2012), pp. 26-41.

Mercader, Yolanda, "La censura en el cine mexicano: una descripción histórica”, en Anuario de Investigación 2009 (2010), pp. 191-215.

Mino, Fernando, La fatalidad urbana, el cine de Roberto Gavaldón, México, Dirección General de Publicaciones, Universidad Nacional Autónoma de México, 2007.

Paxman, Andrew, En busca del señor Jenkins, México, Centro de Investigación y Docencia Económicas, Debate, 2016.

Peredo, Francisco, Cine y propaganda para Latinoamérica. México y Estados Unidos en la encrucijada de los años cuarenta, México, Universidad Nacional Autónoma de México, 2011. 
Pérez Rosales, Laura, “Censura y control. La Campaña Nacional de Moralización en los años cincuenta”, en Historia y Grafía, 37 (2011), pp. 79-113.

Pulido Llano, Gabriela, El mapa 'rojo' del pecado. Miedo y vida nocturna en la ciudad de México 1940-1950, México, Secretaría de Cultura, Instituto Nacional de Antropología e Historia, 2017.

Ramírez, Gabriel, Norman Foster y los otros directores norteamericanos en México, México, Universidad Nacional Autónoma de México, 1982.

Torres Septién, Ramiro, Sombra verde, México, sin editorial, 1949.

Vidal Bonifaz, María del Rosario, "Racionalidad burocrática y dominación carismática: el cine mexicano como estrategia del Estado Nacional en México", en Revista del Centro de Investigación de la Universidad Lasalle, 35 (2011). http://200.10.243.34/ojs/index.php/rci/article/view/147/338. Consultado el 10 de julio de 2018.

Zermeño Padilla, Guillermo, "Cine, censura y moralidad en México. En torno al nacionalismo cultural católico, 1929-1960”, en Historia y Grafía, 8 (1997), pp. 77-102.

Recursos digitales

Academy of Motion Picture Arts and Sciences, "Leonard Goldstein Papers", recuperado el 9 de mayo de 2016 de: http://collections.oscars.org/link/bio/128

Filmografía

Sombra verde (México, 1954). Dirección: Roberto Gavaldón. Producción de Producciones Calderón, Guillermo y Pedro Calderón Stell.

Perdida (México-España, 2011). Dirección: Viviana García Besné. Producción de Arte, Música y Video, S. A de C.V., Viviana García Besné, Alistair Tremps, IMCINE. 
